those drugs which are included in the British National Formulary would be acceptable to the majority, and would still give each individual doctor the right to prescribe as he felt best in special situations. Furthermore, such limitation would actually improve the overall standard of prescribing especially if the advice given in the first half of the B.N.F. was observed. The present machinery, whereby the cost of a doctor's prescribing is kept under review and he is "contacted" if it becomes excessive, could be modified to pay special attention to the non-B.N.F. component as well as to the total cost. In 19723,035 "contacts" were made by regional medical officers as regards doctors prescribing. Only on one occasion was further action taken and eventually a small deduction was made from the doctor's remuneration because of excessive prescribing. In 19732,987 contacts were made but it appears that no further action was taken. I cannot believe that this one case was the only example of persistent overprescribing in two years and I feel that, to be effective, action must be taken far more frequently.

A few years ago two expert panels assessed all the drugs in M.I.M.S. and came to the conclusion that $35 \%$ of the preparations listed were undesirable. While the situation may have improved since, perhaps the time has now come for the D.H.S.S. to refuse to accept financial responsibility for the cost of prescriptions for preparations which are widely held to be undesirable (subject, of course, to reasonable appeal). Such a course would be infinitely preferable to a selective list of prescribable drugs, which would seriously affect the pharmaceutical industry. A strong and reasonably profitable industry is desirable both for future research and also to maintain exports (trade surplus-exports over imports-in 1973 was $£ 154$ million).

\section{Economy and Efficiency}

It is difficult to assess how much money would be saved by these measures, but they should tend to improve the overall standard of prescribing. Certainly far greater economy could be achieved if doctors were more critical of their prescribing and reassessed the need for each prescription carefully instead of just ordering a "repeat" when the patient reattends. (Evidence for overprescribing includes the results of collections of unwanted drugs -1 tons were collected a few years ago in one week in S. Wales.) Too often a p.r.n. prescription for night sedation is given as part of the hospital admission procedure, thus initiating an undesirable addiction. Bronchitics with irreversible airways obstruction frequently receive a useless prescription for bronchodilators when forceful advice about smoking would be more appropriate. Sore throats are often due to a viral infection but, when antibiotics are considered necessary, relatively expensive drugs, such as ampicillin, are often prescribed in place of the therapeutically more desirable drug of choice phenoxymethylpenicillin. Numerous other examples could be mentioned especially in relation to tranquillizers, antidepressants, antirheumatics, and antibiotics where a doctor often appears to be biased towards a particular preparation as a result of advertising rather than consideration of the results of scientific and clinical evaluation.

To conclude I propose that doctors be asked to voluntarily limit their prescribing to drugs recommended in the British National Formulary and that sanctions be more vigorously applied to restrain those who, in the view of their colleagues, regularly overprescribe. If we do not organize this inside the profession, more stringent restrictions may eventually be imposed from outside.

NOEL D. L. OLSEN, M.B., M.R.C.P., Medical Registrar

\section{Do All our Clinicopathological Investigations Pay Off?}

\section{N. K. Shinton}

Like most procedures in medicine, financial evaluation or costeffectiveness of clinicopathological investigations is almost impossible owing to variables such as time saved in hospital beds, time off work by patients, or psychological benefit to the patient-all of which may be influenced by factors other than the results of laboratory investigations. Hence the economic assessment of laboratory procedures is limited to studying costs of staff and equipment in relation to work load. Unfortunately the methods at present employed by the D.H.S.S. for correlating work load with staff are based on the number of requests and tests without any consideration of the enormous differences in the time and technical experience required from one test to another. In haematology the test time may vary from one minute for an erythrocyte sedimentation rate to 120 minutes for a red-cell enzyme assay; manual procedures taking nine minutes can be processed with print-out of results by an automated machine in one. A system of unit values for each test therefore has much to commend it.

Excluding capital development, present laboratory running costs are $80 \%$ for salaries and $20 \%$ for maintenance and replacement of equipment. So if there are to be effective economies in the laboratory service of the N.H.S. the staff/work load ratio must be improved by increasing the availability of equipment able to handle large work loads. Unfortunately the N.H.S. has a long way to go: about 500 laboratories are carrying out haematological tests but 300 of these perform less than 30,000 requests per annum (120 per day). Thus in most haematology laboratories expensive automated equipment would not be cost-effective. On the other hand, many of these laboratories are necessary to cover essential emergency procedures.

\section{Rationalization}

The staff/work load ratio could be improved for manual procedures by limiting the number of laboratories where each test is performed. For many procedures it takes little longer to perform 10 tests than a single one, and this applies similarly to clinical chemistry and to a lesser extent to microbiology. If N.H.S. finances are to be restricted the policy that every district general hospital should have a laboratory offering a complete range of tests cannot be maintained. There are two alternatives: to continue with these laboratories-limiting the number, range, and quality of the tests-or to rationalize the work among the various N.H.S. laboratories. Asking clinicians faced with a rising population of patients to reduce the load on the laboratory is not possible, and reduction in quality means wasted effort. Hence a reduction in the range of routine tests offered by each laboratory is the only solution.

The D.H.S.S. has made a start in rationalization by setting up supraregional laboratories for some procedures. Rationalization is unpopular with both laboratory and clinical staff because inevitably it leads to lack of personal communication, delay in transport of specimens and return of reports, and a lessened attractiveness of a laboratory for training. To some extent these drawbacks can be avoided by preliminary explanation, improved transport, the installation of data processing, and integration of training programmes among laboratories. Unless N.H.S. laboratories become more efficient economically it is unlikely that money will be available in the near future for new developments-and without these interest in medicine will decline and standards of practice fall.

\section{Department of Haematology, Coventry and Warwickshire Hospital,} Coventry CV1 4FH

N. K. SHINTON, M.R.C.PATH., F.R.C.P., Consultant Haematologist

\section{Can We Audit Cost-effectively?}

\section{Hugh Dudley}

I am worried both about the title and the implications of my subject. The title suggests the excessively transatlantic jargon of the economist, though I am relieved to see in the Oxford English Dictionary that one of the first uses of audit was more general, as a "searching examination or solemn rendering of accounts especially the Day of Judgement". Cost-effective is a Johnny-come-lately but has reached the O.E.D. Supplement, probably as a result of Mr. McNamara's stay at the Pentagon in the mid-sixties. If I were patient enough to search through the economic literature I could probably find it well defined, but for me it means that if we spend a penny on analysing what we do we get a penny or more back in the good that accrues to the community. And there's the rub, because, if Mr. McNamara's analysis of the cost of the F 1-11 fighter-bomber versus its strike 
power and the penalties of loss from enemy action were complex, they are nothing to the difficulties of finding out if we are costeffective in either monetary or other terms in our delivery of health care.

The moment the matter is debated we become embroiled in emotion, stuck on the rocks of fixed ideas (for example, patient's expectations and the doctor's background training which fits him for a particular role), and faced with a network of effects which is of a high order of complexity. If I abandon or downgrade the patient with advanced cancer of the stomach in favour of two patients with hernia, how do I make a cost-benefit analysis? How do I equate the loss of six months' dyspepsia-free survival with the economic utility of the return of two breadwinners to work? How trade off, as the jargon goes, the grief of relatives, the ambivalence of the medical and nursing team towards striving for survival or permitting a slip into death's sweet relief, the discomfort of the hernia patient, the economic loss to the community ? This is to mention but a few of the variables in the equations of clinical care.

\section{More Public Inspection}

It is thus scarcely surprising that the medical profession has resolutely avoided the cost-benefit aspects of audit, though there is a growing recognition that we must permit a more public (professional and administrative public that is) inspection of what we do. ${ }^{1}$ Now I am being asked to say whether we should reverse our natural inclinations and take an interest in cost-effectiveness as a phenomenon if not yet as a tool. My answer is yes, not because I believe that we have any firm basis for saying that it can be done with our present knowledge, but because of history and a few contemporary straws in the wind.

First history. The science of operational research grew in the second world war from an analysis of what was practised as distinct from theoretical reviews of what should happen. Techniques developed which enabled those in charge of decision-making to see what was going on and to explore the effects of change by appropriate model making. Ultimately the decision might be taken on grounds which were not part of the analysis, but at least the scenario was laid bare. Therefore, proper study of what goes on can provide the base for profitability.

Secondly, straws in the wind. Because it is such an incomplete

\section{Discussion}

\section{Wanted: Major Changes}

DR. R. A. wOoD: The recent N.H.S. reorganization may not have fulfilled its potential because of industrial action, but the initiatives from the Health Departments have been too concerned with administrative detail and not enough with the function of the Service. Conversely, most clinicians and other workers do not understand that administration will fail without their information and ideas.

To tackle our present problems I propose a series of major changes starting centrally. The most important thing is to accept that there is no more money and to tell area or regional authorities that they must make do with what they have been given. This may cut the number of hospital beds of the traditional high-cost variety and shift the emphasis to primary care.

PROFESSOR H. A. DUDLEY: Dr. Wood's admirable working paper is based on the situation in Scotland, with its Protestant ethic. His ideas about reducing beds and holding the budget exemplify the Calvinistic approach; in Scotland people form a more stable community and are more prepared to work and accept economic rigour; but are such ideas applicable to the less stable community in England, which has changed much faster?

CHAIRMAN: Bed usage is surely linked with clinical freedom. In trying to achieve economies shall we ever get to the stage where a surgeon will have to justify treating a patient with varicose veins inside hospital?

PROFESSOR DUDLEY: You can pressurize a surgeon only after you have analysed the proposals in cost-effective terms. If you treat varicose veins by injection you reduce running costs and save on hospital beds (but not on their overheads), but you then science, medicine finds itself constantly affected by fashion. Hamilton has recently provided a neat example of how without cost-effective auditing such fashions may cause quite unwarrantable expenditure of time and money both by doctor and patient. ${ }^{2} \mathrm{He}$ studied a group of women being screened for breast cancer at a family planning clinic and showed that the examination was just not worthwhile clinically or economically for those under 40 . Though he could not measure it, the lack of worthwhileness must also imply that there were negative features in terms of the needless anxiety aroused by emphasis on the possibility of cancer.

What all this boils down to is finding where resources are being deployed electively or newly and subjecting them to scrutiny. We are neither emotionally nor socially ready to audit the cost-effectiveness of the artificial kidney or renal transplantation; both save lives and relieve manifest suffering at great but acceptable cost. We might be ready to follow up Hamilton's work on breast disease by a more finely-focused study on the over-40s, ${ }^{3}$ and there are other examples of non-killing disorders-such as varicose veins-which have already been or could be subject to a similar scrutiny.

The final difficulty is finding the appropriate machinery and asking the right questions. For obvious reasons we must do it ourselves, but even the conventional audit of a surgical unit such as mine takes about three man-days a month to achieve. We must develop new and better techniques if we are to make anything of this sort of work.

Perhaps the answer to the question posed should really have been "No, not yet." We know so little, we need to know so much more. The remarkable advances made in operational research techniques in the last 25 years have not yet had any great influence on medical practice. A new alternative for the Health Service would be to see that in the next quarter century the possibility that they could is at least explored. I cannot see this as a restriction on clinical freedom, which if ill defined is not absolute. We already restrict ourselves considerably to what is rational; cost-effective or any auditing should be aimed at increasing the domain of reason as a guide to action.

1 Dudley, H. A. F., British Medical fournal, 1974, 1, 275.

2 Hamilton, T., British fournal of Surgery, in press.

3 Chamberlain, J., personal communication.

Department of Surgery, St. Mary's Hospital, London W2

H. A. F. DUDLEY, CH.M., F.R.C.s., Professor of Surgery

PROFESSOR D. N. S. KERR: We already have got restricted freedom - on the length of time you can keep a patient in hospital, for instance. About $10 \%$ of my junior staff's time is spent trying to

find beds, which is scarcely the most efficient use of doctors. spend a little more immediately to cure them surgically you don't have the recurrent costs. Somebody has to take the background decisions-where the savings should be made-and we do not have the knowledge for this.

MR. RUDOLF KLEIN: Aren't there any black and white situations -forms of treatment where everybody would agree that a week of inpatient stay is enough and a fortnight absurd, and that some methods of treatment are more effective than others?

PROFESSOR DUDLEY: No.

PROFESSOR PHILIP RHODES: You can't define effectiveness: there's not the sharp end point that you have in industrial management.

MR. KLEIN : I'm not convinced that medicine is so different. Effectiveness is not a self-evident concept, but that's not saying that it can't be defined by a number of criteria-freedom from pain, comfort, ability to work, etc.

PROFESSOR RHODES: Traditionally in making clinical decisions a doctor has been accountable to his patient and the ethos of medicine, and more recently to the D.H.S.S. and public money. We should not over-emphasize the importance of what one can measure.

\section{Clinical Freedom Restricted Already}

